\title{
Attitudes towards unethical behaviours in organizational settings: an empirical study
}

Daniela Carvalho Wilks (Porto, Portugal)

\section{Introduction}

The incidence of employee misconduct and behavioural deviancy in organizational settings and their potentially adverse effects have attracted considerable attention. Diverse terms have been used to refer to such behaviour namely, unethical behaviour (Jones, 1990), deviant behaviour (Robinson \& Bennett, 1995), dysfunctional behaviour (Griffin et al., 1998), counterproductive behaviour (e.g., Fox \& Spector, 1999), anti-social behaviour (e.g., Robinson et al., 1998), or organizational misbehaviour (e.g.,Vardi \& Wiener, 1996).

These forms of (mis)behaviour cover a wide range of actions from withholding effort to disobeying orders or drug abuse in the workplace. They have been classified as interpersonal and organizational according to whether they are directed towards individuals or the organization, and also according to degree of gravity ranging from minor (showing favouritism) to serious (stealing, verbal abuse) (Robinson \& Bennett, 1995; Bennett \& Robinson, 2000). They have been further divided into extra-organizational and intra-organizational behaviours (Jones, 1990) depending on where they occur, and production deviance, property deviance and personal aggression depending on the target (Robinson \& Bennett, 2000). Some authors point to a difference between destructive deviant behaviour and unethical behaviour. The former has been defined as a set of intentional acts conducted by 
employees that violate organizational norms and potentially harm the organization or its members (Bennett \& Robinson 2000; Robinson \& Bennett, 1995). The latter, by contrast, is 'either illegal or morally unacceptable to the larger community' (Jones, 1991: 367). However, Vardi \& Wiener's (1996:151) definition of organizational misbehaviour covers both organizational norms and social values and 'standards of proper conduct'. According to Appelbaum et al. (2006), while unethical behaviours centre upon the breaking of societal rules, deviant behaviours centre upon the violation of organizational norms. Nonetheless, this distinction is not always clear. Behaviours motivated by loyalty to the organization, such as engaging in deceitful advertising practices or dumping toxic waste in a river, may be considered unethical but not deviant. Conversely, disobeying such orders or blowing the whistle on them may be deemed ethical but deviant, depending on the point of view (social or organizational).

The criteria used to define a given behaviour as deviant are the intention underlying the act, the breach of organizational norms or rules, and the potential damage inflicted on the organization and/or its members. Spreading rumours, the misuse of organizational resources or unauthorized late arrival at work (Robinson \& Bennett, 1995) fall into the category of deviant, while appropriating a few office supplies, using the company telephone for personal long-distance calls or calling in sick when some personal time is needed are included in the category of unethical behaviours (e-g. Jones, 1990). There are behaviours simultaneously unethical and deviant such as jeopardizing the safety of organizational members by not following safety norms. Furthermore, although deviant behaviour is often assumed to be volitional this is not always the case (Marcus \& Schuler, 2004). An employee may compromise safety because drunk or being by nature careless. Other behaviours may be intentional, but are acted upon merely out of self-interest and not intended to cause any harm to the organization or its members. This may be so in the case of taking long breaks, feigning sickness, or being absent longer than necessary. Furthermore, some undesirable behaviours may be considered to fall into 'grey areas' like making personal phone calls at company expense, internet browsing during working hours or using the photocopy machine for private purposes. All these behaviours may fall within the category of minor deviant behaviours (Robinson \& Bennett, 1995), minor offences (see Bordia et al., 2008) or unethical behaviours (Jones 1990), the terms being thus used interchangeably.

From the foregoing it may be inferred that unethical behaviours and deviant behaviours partially overlap. In both cases they imply ethical choices and may have detrimental effects on the organization depending on the moral issue in question. Although the consequences for the organization and its members may be different, 
the underlying motives may be the same. What is perceived as unethical depends to some extent on the issue in question and the seriousness of its consequences. In any event, the most common cases occurring in organizational settings fall into the category of minor offences/unethical behaviours. The degree of acquiescence tends to reflect employee predisposition. It is therefore essential to understand employee attitudes towards them and the factors conducing to their ethical acceptability.

\section{Research overview}

Unethical and deviant behaviours may be attributable to individual characteristics, to organizational climates that encourage unethical decisions, to other factors or to a combination of all of them (see e.g., Kish-Gephart et al., 2010; Sims, 2010). Research on unethical behaviour in organizations has shown that employees may engage in unethical acts in order to benefit themselves, to retaliate against the organization or to harm co-workers (Umphress, et al., 2010). Numerous studies have found that perceptions of unfairness are related to negative outcomes such as theft or using company property for personal purposes, and may thus amount to a deliberate effort to redress perceived injustices or restore equity (e.g., Greenberg, 1990; Tomlinson \& Greenberg, 2006). Research findings have also found a positive association between frustration, anger and deviance (Fox \& Spector, 1999), and retaliation (Starlicki \& Folger, 1997). Furthermore, deviance was shown to be a response to perceived frustrations resulting from organizational power (Lawrence \& Robinson, 2007) or as a retaliatory response to organizational power (Sims, 2010). The violation of the psychological contract was found to be associated with the motivation to seek revenge and engage in workplace deviance (Bordia et al., 2008).

Employees behave according to their relationships with the organization. If they believe the relationship is reciprocal in nature, they tend to behave in ways consistent with organizational norms (see e.g., Umphress et al., 2010). Consequently, employee commitment and organizational identity have been identified as determinants of an individual's feeling and behaviour in organizational settings. Organisational commitment expresses itself as a wish to stay with the organisation, a belief in its goals and a willingness to exert effort on its behalf (Meyer \& Allen, 1997). Commitment has a moral dimension (Ashman \& Winstanley, 2006), and one of its forms consists of a wish to comply with moral obligations (normative commitment as a moral imperative) (see Meyer et al., 2006). Organizational commitment and identification are different constructs but overlap in the sense that both are forms of attachment (Becker \& Bennett, 2006). In this study the term 'organizational commitment' is intended to cover both constructs. 
Extensive research has established that a dissatisfied employee is more likely to be motivated to engage in unethical practices as shown above. However, very few studies have analysed the relationship between job satisfaction and deviant behaviour (Judge et al. 2006). Nevertheless, job satisfaction has been found to be a significant predictor of workplace deviance (Hollinger 1986; Judge et al., 2006; Zoghbi-Manrique-de-Lara, 2010), and to play a mediating role between personality and citizenship behaviours (Ilies et al., 2009). Given the foregoing, it may be inferred that the committed and satisfied employee will be more loyal and less inclined to accept or engage in unethical and deviant conduct.

In spite of the increasing attention given to undesirable behaviours in organizations, there is little to date in way of empirical research into 'the dark side of organizational life' (Vardi \& Wetz, 2004) and since cultural differences frequently define what is 'right' or 'wrong' it is important to examine ethical attitudes in indigenous contexts. As Becker \& Bennett (2006) point out, investigating the link between employees' organizational attachment and deviance may be key to better managing the latter. Few studies to date have scrutinized the possible effects of organizational commitment combined with job satisfaction upon employee acquiescence in unethical or questionably ethical forms of behaviour. This is the aim of the current study, which focuses on unethical behaviours and minor deviant behaviours or minor offences following Jones (1990), Robinson \& Bennett (1995) and Bennett \& Robinson (2000). The term 'unethical' is used to refer to these behaviours and serious offences intentionally carried out are excluded in this study.

\section{The study}

\section{Scope and Purpose}

On the basis of existing research findings, it is hypothesized that both organizational commitment and job satisfaction will be negatively related to the acceptance of unethical behaviours in the work organization. More specifically, the following hypotheses were tested:

H1 - The degree of acceptance of unethical conduct will be negatively associated with organizational commitment;

$\mathrm{H} 2$ - The degree of acceptance of unethical conduct will be negatively associated with job satisfaction.

Additionally, demographic and organizational factors are analysed. 


\section{Method}

\section{Participants}

Participants in this study comprised 126 full-time workers in various occupations and organizations in the north of Portugal, the majority $(78 \%)$ employed in the private sector, 52 percent of them in small size organizations. Fifty six per cent were women. The entire sample was aged between 22 and 57 years old (M39.32,SD8.61) and the majority were married (63\%). Of the respondents, 42 per cent had completed a first degree and 34 per cent a secondary education. Some 5 per cent were bluecollar workers, 67 per cent white collar workers, 21 per cent intermediate management and 7 per cent top management. Organizational tenure ranged between one and 30 years (M 10,60,SD7.99). Participants comprised a convenient sample obtained through 'snowball' sampling method. Over the course of one month, participants were asked to forward a link to the online questionnaire to their colleagues and friends who might be interested in participating. Participants were told that their answers would be totally confidential.

\section{Measures}

In order to assess attitudes towards unethical conducts, a scale was built with items derived from three sources. Seven items were derived from Jones's (1990) Workplace Unethical Behaviours scale and others were taken from Bennett \& Robinson's (2000) and Spector et al. (2006) Counterproductive Work Behaviours lists with their permission. Items included only minor property, production and political deviance (interpersonal) such as chatting excessively with co-workers, stealing company time, doing personal tasks at work, taking extended breaks, slow work rate, using company resources for private business, arriving late to work or leaving early without approval, wasting materials, spreading rumours, showing favouritism, blaming co-workers for mistakes. Only one item: 'ignoring safety procedures endangering oneself and other people' could fall into the category of severe interpersonal aggression. Two items concerning the use of workplace internet for private use were added. The participants were asked to indicate the extent to which they found each behaviour acceptable. On the whole there were 24 items. Five response options were provided ranging from $1=$ very acceptable to $5=$ very unacceptable. Higher scores corresponded to greater acceptability. The Cronbach's alpha coefficient of internal reliability was .90 .

Job satisfaction was assessed with 10 items from the Warr et al. (1979) measure. The scale covers the most important job facets widely used in similar research, covering both intrinsic and extrinsic factors. Respondents were asked to 
rate their degree of satisfaction with each item on 5 Likert scale ( $1=$ from very unsatisfied to $5=$ extremely satisfied). Cronbach's alpha coefficient of internal reliability of the scales was.86.

Organizational identification and commitment were assessed with 6 items adapted from Kim et al (2010) e.g., 'I am part of my work organization' and 'I feel very committed to my company'. (from $1=$ not all to $5=$ very much). Finally, respondents were asked to identify their age, gender, educational level, occupation, the length of employment in the organization and organizational type and size.

\section{Results}

An analysis of the item-total correlation on the unethical behaviour scale revealed that three items ('spreading rumours', 'blaming a co-worker', and 'intentionally making mistakes') contributed significantly less to the scale than the other items. The lowest correlations were for 'blaming a co-worker' and 'intentionally making mistakes' (both .34), and the highest were for 'using working time for personal benefit' (.76). Bivariate analysis revealed that tenure was highly correlated to job satisfaction but not to organizational commitment. A factorial analysis was performed on Job Satisfaction and Organizational Commitment scales and for both one factor was extracted. A mean score was computed for each scale by summing the scores of all items and dividing by their number. Descriptive statistics and Pearson correlations are presented in Table 1.

Table 1. Means, standard deviations and inter-correlations among variables

\begin{tabular}{|c|c|c|c|c|c|c|c|c|}
\hline Variables & $M$ & $S D$ & $\alpha$ & 1 & 2 & 3 & 4 & 5 \\
\hline 1 Acceptance of unethical behaviors & 4.05 & .55 & .90 & - & $.29 *$ & $.34 *$ & $.38 *$ & .15 \\
\hline 2 Job satisfaction & 3.61 & .66 & .86 & $.29 *$ & - & $.71 *$ & .00 & .00 \\
\hline 3 Organizational commitment & 4.05 & .62 & .85 & $.34 *$ & $.71 *$ & - & .06 & .04 \\
\hline 4 Organizational tenure & 10.43 & 7.95 & & $38^{*}$ & .00 & .06 & - & $.61 *$ \\
\hline 5 Age & 39.32 & 8.61 & & .15 & .00 & .04 & $.61 *$ & - \\
\hline
\end{tabular}

According to the findings, the most accepted behaviours (ranging between 3 'I am not sure' and 4 'unacceptable') were, in order, 'reading private emails during working hours' (M3.05;SD1.22), 'making a personal copy on the organization photocopy machine' (M3.33;SD1.22), 'browsing the internet for personal benefit' (M3.36;SD1.18), 'using working time for private benefit' (M3.49;SD1.11), 'using the 
organization car to make a personal trip' (M3.60:1.19), 'showing favouritism' (M3.67;SD1.16), 'staying in the most expensive hotel' (M3.79;SD1.12), 'taking home a few office supplies' (M3.87;SD1.05), and 'making up excuses for coming to work late or leaving earlier' (M3.87;SD1.06), 'talking with co-workers instead of working' (M3.91;1.16), 'using the organization telephone for a personal long-distance call' (M3.94;SD1.06), and 'undermining the authority of the director or supervisor by not following his/her orders'(M3.98;SD1.00). The most unacceptable behaviours were 'purposely doing work incorrectly' (M4.71;SD.74), followed by 'ignoring safety procedures endangering himself/herself and other people' (M4.67;SD.56) and 'telling other people outside what a lousy place you work for' (M4.67;SD.53), and 'spreading rumours about a co-worker' (M4.63;SD.79). The non-acceptable responses tended to aggregate at the extreme end of the scale. For instance, whereas 'telling other people outside what a lousy place you work for' was considered to be totally unacceptable by 70 per cent of the participants, 'taking home office material' was considered totally unacceptable by 30 per cent.

No significant differences were found for sex, organization type and size, and organizational function. However, differences in respect to age $(\mathrm{F}(2)=5.33, \mathrm{p}<.05)$, organizational tenure $(\mathrm{F}(2)=6.90, \mathrm{p}<.05)$, and education $(\mathrm{F}(4)=7.49, \mathrm{p}<.001)$ were statistically significant. Regarding the latter, acceptance of unethical behaviours lowered with the level of education (basic education M4.58, SD.35; first degree M3.82,SD.54). Organizational tenure and degree of acceptance were positively correlated $(\mathrm{r}=.38, \mathrm{p} .>.001)$ and participants with an organizational tenure of less than 10 years had lower levels of acceptance (M 3.90, SD.54) than those with longer tenure (M4.38,SD.43). No association was found between organizational tenure and either organizational commitment or job satisfaction.

In order to assess the relations between acceptance of unethical behaviours and the two independent variables, in addition to examining the zero-order correlations a two-step hierarchical regression was run, entering tenure at Step 1, and job satisfaction and organizational commitment at Step 2. As can be seen in Table 2, the contribution of organizational tenure is the largest contribution to the model followed by organizational commitment. 
16 | Daniela Carvalho Wilks

Table 2. Multiple regression results for acceptance of unethical behaviors

\begin{tabular}{llll}
\hline & $B$ & $S E$ & $\beta$ \\
\hline Step1 & 3.80 & .08 & \\
Constant & .03 & .00 & $.38^{* *}$ \\
Ten re & & & \\
\hline Step 2 & 2.43 & .30 & \\
Constant & .03 & .00 & $.36^{* *}$ \\
Tenure & .23 & .10 & $.26^{*}$ \\
Commitment & .13 & .09 & .15 \\
Job satisfaction & & & \\
\hline
\end{tabular}

Note: $\mathrm{R}^{2}=.14$ for Step $1, \Delta \mathrm{R}^{2}=.27$ for step $2 ; * \mathrm{p}<.05 ; * * \mathrm{p}<.001$.

\section{Discussion and conclusion}

On the whole findings provide support for the hypotheses. Organizational commitment and job satisfaction were found to be negatively associated with acceptance of unethical behaviours. However, the association was much weaker for job satisfaction. An explanation for this could be that, although highly associated, these constructs are in fact different and this is reflected in the degree of acceptance of unethical behaviours. It is worth noting that Mangione \& Quinn (1975) found a significant association between job satisfaction and counterproductive behaviours only amongst men aged 30 or over.

Organizational tenure was the factor with most impact on the acceptance of unethical behaviours, which is consistent with previous research. For instance, Sims (2002) found that tenure was a significant factor in the likelihood of reported ethical rule breaking. Since tenure was not associated with either organizational commitment or job satisfaction, it may be concluded that its effects are independent of the other two. Sims argues that long tenure employees may have more to lose in breaking the rules. Another possible explanation is that they may have more fully internalised organizational norms and expectations. As Wiener (1982) asserts, 
organizational commitment is about behaving according to organizational interests. This being the case, the lower acceptance of unethical behaviours might simply be a corollary of adaptation. This is an interesting point at a juncture when job tenure is being eroded due to the phasing out of jobs for life.

Still another possible explanation is that the degree of acceptance of unethical behaviours reflects an attitude towards the organization. However, the relationship may not be straightforward. The employees' reference and identity group may count more in the shaping of attitude than the organization in general. If the main source of reference is the professional group, what is regarded as acceptable is likely to be informed more by deontological principle rather than their work organization, though these may well coincide. An employee may have little commitment to the organization, but still be actuated by professional codes.

Attitudes assessed by the degree to which a person accepts or not a given behaviour is clearly not tantamount to actually engaging in it, but gives an insight into how employees feel about a specific form of conduct. In analysing the results however, it must be kept in mind that the behaviours analyzed excluded those that could cause serious harm to the organization and/or its members. It is significant that the most accepted behaviours were motivated merely by personal advantage, such as taking office supplies home or reading private emails, while those deemed most unacceptable could potentially cause harm either to the organization or its members. Interesting to note is that, despite cultural and other differences, participants in this study showed a similar hierarchy of acceptance to those in Jones's (1990) study. In both cases, using the copying machine was considered to be more acceptable than using the telephone, taking office supplies home or using the company car.

Findings are in line with research that did not find any sex and age differences concerning ethical issues (see O'Fallon \& Butterfield, 2005 for a review). Similarly, no difference was found for organizational position; participants in management positions actually showed a degree of acceptance higher than those in lower positions although differences were not statistically different. In this respect, it is worth noting that Jones's (1990) findings showed that hierarchical position (president versus employee) had an impact on the perceived acceptability of unethical behaviours, although Murdack (1993) did not find such differences.

A surprising result was that education levels were negatively associated with the degree of acceptance. To this author's knowledge there are no studies analysing the effect of education on the acceptance of unethical behaviours but literature reviews on ethical decision-making indicate either that education has little or no 
influence, or that higher education levels are associated with greater ethical sensitivity (Loe et al., 2000).

This study sheds light on employees' attitudes towards the acceptance of unethical behaviours. It also contributes to the literature on the subject and, by analysing a Portuguese population, generalizes previous findings. However, limitations should be acknowledged. A major limitation is that undesirable behaviours are especially difficult to assess due to the potential for social desirability bias. Future studies should therefore include a measure of social desirability and a multi-source approach. Another potential limitation is that the use of scales does not provide insight into the reasons for acceptance or non-acceptance of a given behaviour. As Spector et al. (2006) point out, emotions are not the only motive for engaging in counterproductive behaviours. There are also rational calculations and other impulses that can only be captured by the use of qualitative methodology. Still another limitation is the cross-sectional design and finally, the sample size of the present study, both of which limit the generalization of results. As a result future studies should use longitudinal methods and extend the scope by the addition of other samples.

This study suggests that both organizational commitment, job satisfaction and tenure are key parameters in framing the acceptance of undesirable behaviours in organizations. In consequence, these are clearly factors to be taken into consideration in order to reduce the occurrence of such behaviours.

\section{References}

Appelbaum, S.H., Shapiro, B.T., \& Molson, J. (2006). Diagnosis and remedies for deviant workplace behaviors. Journal of American Academy of Business, 9, 14-20.

Ashman, I. \& Winstanley, D. (2006). The ethics of organizational commitment. Business Ethics: A European Review, 15, 142- 153.

Becker,T.E. \& Bennett, R.J. (2006). Employee attachment and deviance in organizations. In J. Langan-Fox, C. Cooper., \& R. Klimoski (Eds.), Research Companion to the Dysfunctional Workplace: Management Challenges and Symptoms (pp.136-151). Cheltenham, UK and Northampton, USA: Edward Elgar.

Bennett, R.J. \& Robinson, S.J. (2000). Development of a measure of workplace deviance. Journal of Applied Psychology, 85, 349-360. 
Bordia, P. Restubog, S.L., \& Tang, R.L. (2008). When employees strike back: Investigating mediating mechanisms between psychological contract breach and workplace deviance. Journal of Applied Psychology, 93, 1104-1117.

Fox, S. \& Spector, P.E. (1999). A model of work frustration-aggression. Journal of Organizational Behavior, 20, 91-931.

Greenberg, J. (1990). Employee theft as a reaction to underpayment inequity: The hidden cost of pay cuts. Journal of Applied Psychology, 75, 561-568.

Griffin, R.W., O'Leary-Kelly, A.M., \& Collins, J. M. (1998). Dysfunctional work behavior in organizations. In C.L. Cooper \& D.M. Rousseau (Eds.), Trends in Organizational Behavior (pp.65-82). New York: Wiley.

Hollinger,R.C. (1986). Acts against the workplace: Social bonding and employee deviance. Deviant Behavior, 7, 53-75.

Ilies, R. Fulmer, IS. Spitzmuller, M., \& Johnson, M.D. (2009). Personality and citizenship behaviour: the mediating role of job satisfaction. Journal of Applied Psychology, 94, 945-959.

Jones, T.M. (1991). Ethical decision making by individuals in organizations: An issue-contingent mode. Academy of Management Review, 16, 366-395.

Jones, W.A.(1990). Student views of 'ethical' issues: A situational analysis. Journal of Business Ethics, 9, 201-205.

Judge, T.A. Scott, B.A., \& Ilies, R. (2006). Hostility, job attitudes, and workplace deviance: Test of a multilevel model. Journal of Applied Psychology, 91, 126-138.

Kim, H-R., Lee, M., Lee, H-T., \& Kim, N-M (2010). Corporate social responsibility and employee-company identification. Journal of Business Ethics, 95, 557-569.

Kish-Gephart, J.J., Harrison, D.A., \& Treviño, L.K. (2010). Bad apples, bad cases, and bad barrels: Meta-analytic evidence about sources of unethical decisions at work. Journal of Applied Psychology, 95, 1-31.

Klein, H. J., Becker, T.E., \& Meyer, J.P. (2009). Commitment in Organizations (SIOP Organizational Frontiers Series). New York and London: Routledge.

Lawrence, T. B. \& Robinson, S. L. (2007). Ain't misbehavin: Workplace deviance as organizational resistance. Journal of Management, 33, 378-394.

Loo, T.W., Ferrell, L., \& Mansfield, P. (2000). A review of empirical studies assessing ethical decision making in business. Journal of Business Ethics, 25, 185-204.

Mangione, T.W. \& Quinn, R.P. (1975). Job satisfaction, counterproductive behavior, and drug abuse at work. Journal of Applied Psychology, 60, 114-116. 
20 | Daniela Carvalho Wilks

Marcus, B. \& Schuler, H. (2004). Antecedents of counterproductive behavior at work: A general perspective. Journal of Applied Psychology, 89, 647-660.

Meyer, J. \& Allen, N.(1997). Commitment in the Workplace: Theory, Research, and Application. Sage: Thousand Oaks.

Meyer, J.P., Becker, T.E., \& van Dick, R. (2006). Social identities and commitments at work: Toward an integrative model. Journal of Organizational Behavior Special Issue: Commitment and Identification: Forms, Foci, and Future, 27, 665-683.

Mudrack, P. (1993). An investigation into the acceptability of workplace behaviors of a dubious ethical nature. Journal of Business Ethics, 12, 517-524.

O'Fallon, M. \& Butterfield, K. D. (2005). A review of the empirical ethical decisionmaking literature: 1996-2003. Journal of Business Ethics, 59, 375-413.

Robinson, S. L. \& Bennett, R. (1995). A typology of deviant behaviors: A multidimensional scaling study. Academy of Management Journal, 38, 555-572.

Robinson, S. \& O'Leary-Kelly, A.M. (1998). Monkey see, monkey do: The influence of work groups on the antisocial behavior of employees. Academy of Management Journal, 41, 659-672.

Sims, R.L. (2002). Ethical rule breaking by employees: A test of social bonding theory. Journal of Business Ethics, 40, 101-109.

Sims, R. L. (2010). A study of deviance as a retaliatory response to organizational power. Journal of Business Ethics, 92, 553-563.

Skarlicki, D.P. \& Folger, R. (1997). Retaliation in the workplace: The roles of distributive, procedural, and interactional justice. Journal of Applied Psychology, 82, 422-443.

Spector, P. E. (1997). The role of frustration in antisocial behavior at work. In R.A.Giacalone \& J.Greenberg (Ed.), Antisocial Behavior in Organizations (pp.117). Thousand Oaks, CA:Sage.

Spector, P.E., Fox, S., Penney, L.M., Bruusema, K., Goh, A., \& Kessler, S. (2006). The dimensionality of counterproductivity: Are all counterproductive behaviors created equal? Journal of Vocational Behavior, 68, 446-460.

Tomlinson, E. C. \& Greenberg, J. (2006). Understanding and deterring employee theft with organizational justice. In J. Langan-Fox, C. Cooper. \& R. Klimoski (Eds.), Research Companion to the Dysfunctional Workplace: Management Challenges and Symptoms (pp.285-301). Cheltenham, UK and Northampton, USA: Edward Elgar. 
Umphress, E. E. Bingham, J. B., \& Mitchell, M.S. (2010). Unethical behavior in the name of the company: The moderating effect of organizational identification and positive reciprocity beliefs on unethical pro-organizational behavior. Journal of Applied Psychology, 95, 769-780.

Vardi, Y. \& Wiener, Y. (1996). Misbehavior in organizations: A motivational framework. Organization Science, 7, 151-165.

Vardi, Y. \& Weitz, E. (2004). Misbehavior in Organizations: Theory, Research, and Management. Mahwah, N.J.: Erbaum.

Warr, P. Cook, J. \& Wall, T. (1979). Scales for the measurement of some work attitudes and aspects of psychological well-being. Journal of Occupational Psychology, 52, $129-148$.

Wiener, Y. (1982). Commitment in organizations: A normative view. Academy of Management Review, 7, 418-428.

Zoghbi-Manrique-de-Lara, P. (2010). Employee deviance as a response to injustice and task-related discontent. The Psychologist-Manager Journal, 13, 131-146. 
Daniela Carvalho Wilks (Porto, Portugal)

\title{
Attitudes towards unethical behaviours in organizational settings: an empirical study
}

\begin{abstract}
Employee misconduct is prevalent in organizations and may be counterproductive in social and material terms. It is thus important to better understand how misconduct is construed by employees and the factors that determine its ethical acceptability in specific cases. This study explores attitudes towards unethical and minor deviant behaviours by examining the degree of acquiescence towards them in a sample of employees. Based on previous studies it was hypothesized that both organizational commitment and job satisfaction would be negatively related to the acceptance of such behaviours in organizational settings. Results show that there is a relationship between the degree of acquiescence and organizational commitment and a more modest relationship with job satisfaction. They further indicate that organizational tenure impacts very significantly on the degree of acceptance. Although differences were found for age, neither gender nor organizational variables were found to be significant.
\end{abstract}

Keywords. Unethical behaviour, organisational identification, job satisfaction.

Author. Daniela Carvalho Wilks holds an MA and Ph.D. from The University of Sheffield and is currently an associate professor at the Department of Economics and Management Sciences of Universidade Portucalense, where she teaches Business Ethics and Corporate Social Responsibility and Management Psychology.

Contact Address. Universidade Portucalense, Department of Economics and Management Sciences, Rua Antonio Bernardino Almeida, 4200-072 Porto, Portugal. Professional email: damflask@upt.pt. Private email: Daniela.wilks@clix.pt.

Citations. Reference this paper as: Carvalho Wilks, D. (2011). Attitudes towards unethical behaviours in organizational settings: an empirical study. Ethics in Progress Quarterly, Volume 2, Issue 2, pp. 9-22, available online at ethicsinprogress.org. 